\title{
Biodiversity of Ticks and Fleas of Dogs in the Western Balkans - Preliminary Examinations
}

\author{
Ivan PAVLOVIĆ*1, Srđan JOVČEVSKI ${ }^{2}$, Dragan ROGOŽARSKI ${ }^{3}$, Ferenc CSORDÁS ${ }^{4}$, Novalina \\ MITROVIĆ ${ }^{5}$, Irina MIJATOVIĆ ${ }^{6}$, Doroteja MARČIĆ ${ }^{7}$, Živka ILIĆ ${ }^{1}$, Dragan ĆIRKOVIĆ ${ }^{8}$, Milanko \\ ŠEKLER ${ }^{9}$, Stefan JOVČEVSKI ${ }^{2}$, and Marko RISTIĆ ${ }^{10}$
}

${ }^{1}$ Scientific Veterinary Institute of Serbia, 11000 Belgrade, Serbia

2 Veterinarna Clinic "I N O-VE T", 1300 Kumanovo, R.Macedonia

${ }^{3}$ Veterinary Specialistic Institute Požarevac, 12000 Požarevac, Serbia

${ }^{4}$ Veterinary Ambulance FeriTom, 23000 Zrenjanin, Serbia

${ }^{5}$ Veterinary Institute”Teolab”, 76000 Dvorovi Bijeljina, Republic Srpska (BiH)

${ }^{6}$ Veterinary Diagnostic Laboratory Podgorica, 81101 Podgorica, Montenegro

${ }^{7}$ Scientific Veterinary Institute Novi Sad, 21000 Novi Sad, Serbia

${ }^{8}$ State University of Novi Pazar, Dep.of Chemical-Technological Sciences, 36300 Novi Pazar, Serbia

${ }^{9}$ Veterinary Specialistic Institute Kraljevo, 36000, Kraljevo,Serbia

${ }^{10}$ Veterinary Zavod Subotica, 24000 Subotica,Serbia

*Corresponding author: dripavlovic58@gmail.com

\begin{abstract}
s
Ticks and fleas infestation is the most common ectoparasitic condition of dogs with worldwide distribution. In period 2011-2013 we performed preliminary study on the biodiversity of ticks and flea of dogs, from the Western Balkan area. Parasites were collected from dogs in veterinary practices from several cities in various part of Serbia, Macedonia, Republic Srpska (BiH) and Montenegro. During of the study of relative abundance analysis revealed that the species Ixodes ricinus was absolutely dominant, followed by Rhipicephalus sanguineus, Dermacentor marginatus and D. reticulatus. At same examinations three flea species were found at dogs Ctenocephalides felis felis was the most abundant, followed by Ctenocephalides canis and Pulex irritans.
\end{abstract}

Keywords: fleas, ticks, dogs, west Balkan

\section{INTRODUCTION}

Ticks and fleas infestation is the most common ectoparasitic condition of dogs with worldwide distribution. They also spread a number of serious human diseases and they are the most important vectors in veterinary field (Rinaldi et al., 2007). Ticks are a widespread problem for dogs. Beside the medical importance of ticks, the economical damages that they can cause are also significant. Although difficult to measure precisely, the global economic impact of ticks and tick-borne diseases is believed to be in many billions of dollars (Jongejan and Uilenberg, 2004; Pavlović et al., 2012). Fleas are small, agile, usually dark colored, wingless insects with tube-like mouth-parts adapted to feeding on the blood of their hosts. Flea infestation is the most common ectoparasitic condition of dogs and cats with worldwide distribution (Földvári and Farkas,2005). This wide distribution and the fact that fleas are major nuisance pests a matter of public health and the source of flea allergic dermatitis (FAD), one of the most common causes for the presentation of dogs to the veterinarian, make control definitely necessary (Dryden and Rust,1994; Jongejan and Uilenberg, 2004 ).

Prevalence of ticks and fleas cats of dogs is examined worldwide. Concentrating on pets, particularly on cats and dogs, only a restricted number of species occur in large amounts with any regularity to be of importance as nuisance 
pests. Faunistic and epidemiologica examination of tick fauna at Europa established dominate presence of hard ticks especially Ixodes ricinus and ticks from familly Rhipicephalus spp., Dermacentor spp., Haemaphysalis spp, Hyalloma spp and Boophilus spp. (Milutinović et al., 1996,1997,1988; Omeragić, 2011; Dumitrache et al., 2012; Pavlović et al., 2003, 2011, 2014). Most abundant fleas species are Ctenocephalides felis felis, the cat flea, Ctenocephalides canis, the dog flea, Pulex irritans, the human flea, and Echidnophaga gallinacea as well as Ceratophyllus gallinae, fleas found on poultry (Kalvelage and Münster,1991; Beck et al., 2006; Bond et al., 2007; Rinaldi et al., 2007; Farkas et al., 2009; Pavlović et al., 2011).

From an ongoing country-wide study on the spectrum, the epidemiology and the population dynamics of ticks and flea infestations in dogs, important preliminary results from the areas of Western Balkan area. In our paper we presented preliminary results of examination of biodiversity of ticks and fleas of dogs in Western Balkan area in period 2011-2013.

\section{MATERIALS AND METHODS}

Parasites were collected from dogs in veterinary practices from several cities in various parts of Serbia (Belgrade, Pozarevac, Novi Sad,Zrenjanin, Subotica and Novi Pazar), Macedonia (Kumanovo area), Republic Srpska (BiH) (Bijeljina area) and Montenegro (dogs that have been with owners on summer vacation) between 2010 and 2013 . We examined total of 1484 dogs. In Serbia we examined 1232 dogs, Macedonia 91, Republic Srpska 98 and Montenegro 63.

All dogs appearing for a clinical veterinary consultation were clinically examined. Dogs were examined irrespective of any kind of prior therapeutic or prophylactic insecticidal treatment. Fount ticks and fleas were preserved in 95\% ethanol before identification.

All specimens were placed into plastic bottles which had a piece of hard paper inserted bearing the name of locality name of host and date of collection. Determinate of fleas and ticks were performed at Scientific Veterinary Institute of Serbia in Belgrade using morphological criteria. The tick species were determinate using keys by Pomerancev (1950) and Kapustin (1955) and fleas by using keys by Krasnov (2006).

\section{RESULTS AND DISCUSION}

During our study infection with tick we occurred at $921(62.02 \%)$ and with adult fleas at 391 (26.34\%) of examined dogs. In all dogs regardless of the areas from which they originated was identical fauna of ticks and fleas as well as the prevalence, with minimal deviations that were not statistically significant.

The result showed presence of 4 species of ixodid ticks. Most abundant species was Ixose ricinus and followed by Rhipicephalus sanguineus, Dermacentor marginatus and D. reticulatus. At same examinations three flea species were found at dogs Ctenocephalides felis felis was the most abundant, followed by Ctenocephalides canis and Pulex irritans.

TICKS - The study of relative abundance analysis revealed that the species Ixodes ricinus was absolutely dominant found at $46.03 \%$ (424/921) dogs, followed by Rhipicephalus sanguineus at 29.85\% (275/921), Dermacentor marginatus at $13.26 \%(122 / 921)$ and D. recticulatus at $10.85 \%$ $(100 / 921)$ dogs. Moreover, the sex ratio within individual species showed a higher number of females in 3 species (Ixodes ricinus, Rhipicephalus sanguineus and Dermacentor marginatus), and an equal number of male and female ticks in one species, Dermacentor recticulatus.

The population dynamics of recorded tick species are known for their two maxima a year in spring (April-May) and in autumn (SeptemberOctober). The considerable interchange between spring and autumn tick populations can be attributed mainly to environmental conditions. Dermacentor marginatus and D.recticulatus occurred population maximum in April. May was the month of the population peak for I.ricinus and it was noted that this species started to decrease in abundance in June. R.hipicephalus sanguineus reached their maxima decreasing gradually until August, and disappearing completely in Septembar and October. The autumn population peak in Septembar and in October occurred for the I.ricinus, and Dermacentor marginatus (Milutinović et.al., 1996,1997,1988; Pavlovićet al., 2002) .

If we compared our results with results performed in other countries in the region, Romania, Greece and Hungary, we concluded that dominate tick species at dogs were Ixodes ricinus, Rhipicephalus sanguineus and Dermacentor marginatus (Pavlović et al., 2002; Papazahariadou et 
al., 2003; Dumitrache et al., 2012; Mihalca et al., 2012).

FLEA - Three flea species were found parasitizing dogs. Ctenocephalides felis felis was the most abundant found at $71.86 \%(281 / 391)$ of fleas identified, followed by Ct.canis at $21.22 \%$ (83/391) and Pulex irritans at 4.34\%(17/391). Ct. canis and P. irritans abundances were higher during the warm period of the year. Mean annual temperature was negatively correlated with overall, Ct. canis and P. irritans abundances, but positively related to $C$ t.felis felis abundance.

Our results are similar like results of examination performed in Italy, UK, FYRM, or Croatia (Beck et al., 2006; Bond et al., 2007; Rinaldi et al., 2007; Pavlović et al., 2014), who occurred that Ct.felis felis was most abundance at dogs. At same time examination performed by Farkas et al. (2009) induced that Ct.canis was most abundant flea's species in dogs and cats in Hungary.

The highest infestation rates for dogs were detected between Jun and October, and for cats between July and September, the lowest infestation rates for dogs were observed between November and May. Although the prevalence was generally higher during the summer months, no statistical differences were detectable when looking at the pattern between the four seasons, interestingly; the highest prevalence in dogs was detected in June and comparatively, in cats in August. The lowest detection rates in dogs were seen in March and in cats in January. The preliminary results did not indicate any tendency for a relationship between climatic conditions and flea infestation rates (Kalvelage and Münster, 1991; Cruz-Vazquez et al., 2003).

Results of our examination of season distribution of fleas were similar like results of examination performed in various parts of Europe. In Germany the highest infestation rates for dogs were detected between July and October, and for cats between July and September, the lowest infestation rates for dogs were observed between November and May, and for cats between November and April (Pavlović et al., 2011). In southern Italy the prevalence was higher during the period between June and October (Rinaldi et al., 2007). In Hungary, the highest prevalence of infestation on dogs occurred in August and the lowest in May (Farkas et al., 2009).
In general, the abundance of adult cat fleas fluctuates with seasonal changes. The warm months of spring and summer give rise to the highest numbers, whereas few are found during the cold months of late fall and winter. Infestations of cat fleas consistently recur during the warm months of the year. Furthermore cat flea populations are rarely detected on domestic hosts during winter months, but reinfestation of unknown origin are nevertheless common in spring and summer.

\section{CONCLUSIONS}

Ticks and fleas infestation is the most common ectoparasitic condition of dogs with worldwide distribution. They also spread a number of serious human diseases and they are the most important vectors in veterinary field. In the period 20112013 in the Western Balkans has done preliminary examined species of ticks and fleas that infect dogs and their seasonal distribution. Parasites were collected from dogs in veterinary practices from several cities in various part of Serbia, Macedonia, Republic Srpska (BiH) and Montenegro. During of the study of relative abundance analysis revealed that the Ixodes ricinus was absolutely dominant, followed by Rhipicephalus sanguineus, Dermacentor marginatus and Dermacentor reticulatus. At same examinations three flea species were found at dogs. Ctenocephalides felis felis was the most abundant, followed by Ctenocephalides canis and Pulex irritans. These studies point to the need to carry out a more comprehensive study that would include dogs and certain diseases transmitted by ticks.

Acknowledgements. I thank to all my colleagues from veterinary clinics and ambulances in Serbia, Macedonia, Republic Srpska (BiH) and Montenegro who helped us in collecting samples and data so that we do this research.

\section{REFERENCE}

1. Beck W, Boch K., Mackensen H., Wiegand B. and Pfister K. (2006).Qualitative and quantitative observations on the flea population dynamics of dogs and cats in several areas of Germany, Vet Parasitol. 137(1-2):130-136.

2. Bond R, Riddle A, Mottram L, Beugnet F and Stevenson R (2007). Survey of flea infestation in dogs and cats in the United Kingdom during 2005. Vet Rec, 160(15):503-506.

3. Cruz-Vazquez C, Castro Gamez E, Parada Fernandez M and Ramos Parra M (2001). Seasonal occurrence of 
Ctenocephalides felis felis and Ctenocephalides canis (Siphonaptera: Pulicidae) infesting dogs and cats in an urban area in Cuernavaca, Mexico, J Med Entomol. 38(1):111-113.

4. Dryden MW. and Rust MK (1994). The cat flea: biology, ecology and control, Vet Parasitol. 52(1-2):1-19.

5. Dumitrache MO, Gherman CM, Cozma V, Mircean V., Györke A, Sándor AD and Mihalca AD (2012). Hard ticks (Ixodidae) in Romania: surveillance, host associations, and possible risks for tick-borne diseases Parasitol Res 110:2067-2070.

6. Farkas R, Gyurkovszky M, Solymosi N and Beugnet F (2009). Prevalence of flea infestation in dogs and cats in Hungary combined with a survey of owner awareness, Med Vet Entomol. 23(3):187-194.

7. Földvári $G$ and Farkas R (2005). Ixodid tick species attaching to dogs in Hungary. Vet Parasitol 129:125-131.

8. Jongejan F and Uilenberg G. (2004). The global importance of ticks. Parasitol. 129 Suppl:S3-14.

9. Kapustin FU (1955). Atlas parazitov krovi životnih i klešćei iksodid.Gasudarstvenoe izdetejlstvo seljskohazjajstvenoi literaturi, Moskva.

10. Kalvelage H and Münster M (1991). Ctenocephalides canis and Ctenocephalides felis infestations of dogs and cats. Biology of the agent, epizootiology, pathogenesis, clinical signs, diagnosis and control, Tierarztl Prax. 19(2):200206.

11. Krasnov BR, Functional and Evolutionary Ecology of Fleas, A Model for Ecological Parasitology, ed.Cambridge University Press, Cambridge,2006

12. Mihalca AD, Dumitrache MO, Magdaş C, Gherman CM, Domşa C, Mircean V, Ghira IV, Pocora V, Ionescu DT, Sikó Barabási S, Cozma V and Sándor AD (2012). Synopsis of the hard ticks (Acari: Ixodidae) of Romania with update on host associations and geographical distribution. Exp Appl Acarol. 58(2):183-206. doi: 10.1007/s10493-0129566-5

13. Milutinović M, Petrović Z, Bobić B And Pavlović I (1996). Ecological notes on ticks colected in West Serbia, Yugoslavia. Parasit.Hung. 29-30:67-74.
14. Milutinović M, Aleksić-Bakrač N and Pavlović I (1997). Ticks (Acari: Ixodidae, Argasidae) in the Belgrade area. Acta Entom.Serb.2:77-85

15. Milutinović M, Aleksić-Bakrač N and Pavlović I (1997/8). Faunistic and ecological notes on ticks (Acari: Ixodidae,Argasidae) in the extended area of Belgrade. Magy. Allator. Lapja 120:434-436.

16. Milutinović M, Aleksić-Bakrač N and Pavlović I (1998). Reserch of tick population (Acari: Ixodidae) in Eastern part of Serbia. Ars Vet. 14 (2): 227-234.

17. Omeragic J (2011). Ixodid ticks in Bosnia and Herzegovina. Exp.App. Acarolo.53(3):301-309.

18. Papazahariadou MG, Saridomichelakis MN, Koutinas A., Papadopoulos EG and Leontides L (2003). Tick infestation of dogs in Thessaloniki, northern Greece. Med Vet. Entomol. 17:110-113.

19. Pavlović I, Milutinović M, Petković D, Terzin V and Terzin D (2002). Epizootiological research of canine babesiosis in the Belgrade district. J. Protozool. Res.12 (1-2): 10-15.

20. Pavlović I, Petković D, Rogožarski D, Stojanovic D, Hadžić I, Terzin V, Stokić-Nikolić S, Rajković. and Anđelić-Buzadžić G (2011). Flea infestation of dogs and cats in Serbia. Lucr. St.Med.Vet. XLIV(1): 26-30.

21. Pavlović I, Petković D, Kukovska V, Stamenković V, Jovčevski S, Pavlović M, Jovčevski S and Elezović M (2012). Most important food-borne disease of dogs caused by ticks and its control Book of Proceedings 3rd International Scientific Meeting Days of Veterinary Medicine 2012, 0204.9.2011., Ohrid, Macedonia, 34-37.

22. Pavlović I, Jovčevski Sr, Jovčevski S., Kukovska V and Dimitrić A (2014) Tick fauna of sheep and cattle at Kumanovo arae (Macedonia). Lucr.Stii.Med.Vet. XLVII (3): 88-95.

23. Pomerancev BL (1950). Fauna SSSR. Paukobraznie. Iksodovie kleščei (Ixodidae) Izd. Akademem Nauk SSSR, Moskva-Leningrad.

24. Rinaldi L, Spera G, Musella V, Carbone S, Veneziano V, Iori A and Cringoli G (2007). A survey of fleas on dogs in southern Italy, Vet Parasitol. 148(3-4): 375-378. 